\title{
Diagnóstico de déficit de atención versus la familia como recurso terapéutico
}

\author{
Diagnosis of Attention Deficit versus the Family as a Therapeutic Resource \\ Cristina Domínguez SÁNCHEZ \\ Grupo Zurbano de Terapia Familiar \\ crisdominguez.11@gmail.com \\ Alfonsa RodRÍGUEZ RoDRíGUEZ \\ Universidad Complutense de Madrid \\ alfrodri@trs.ucm.es
}

Recibido: 19/07/2013

Revisado: 19/07/2013

Aceptado: 12/11/2013

Disponible on line: 20/12/2013

\section{Resumen}

En el presente artículo se lleva a cabo una reflexión acerca del cambio de paradigma en la conceptualización del trastorno de déficit de atención, al incorporar en el abordaje terapéutico, la evaluación de la familia con una perspectiva sistémica, al trabajar no sólo con el paciente que porta el síntoma, sino también con el sistema en el que está inserto, es decir, su núcleo familiar. Se analizará la intervención que se realizó con una familia que acudió a nuestro centro con la desesperación de años enrolados en diferentes tratamientos y estilos terapéuticos, debido a la enfermedad de uno de sus miembros.

Palabras clave: Intervención socio-familiar sistémica, diagnóstico, trastorno, diferenciación.

\begin{abstract}
:
This article is a reflection on the paradigm shift in the conceptualization of attention deficit disorder, having incorporated family assessment from a systemic perspective into the therapeutic approach, working not only with the patient exhibiting the symptoms, but also with the system within which the patient is embedded, that is, the nuclear family. The procedure done with a family who came to our office, desperate after years of enrollment in different treatments and therapeutic styles due to the illness of one of its members, will be analyzed.
\end{abstract}

Keywords: Systemic socio-family intervention, diagnosis, disorder, differentiation.

Referencia normalizada: Domínguez Sánchez, C., Rodríguez Rodríguez, A. (2013): «Diagnóstico de déficit de atención versus la familia como recurso terapéutico». Cuadernos de Trabajo Social, 26(2): 295-303.

Sumario: Introducción. 1. Niños problemáticos, niños con trastornos, familias con dificultades. 2. La familia Soler. 3. El niño que transita por diferentes subsistemas. 4. Días de reflexión: el camino para el cambio. 5. Conclusiones. 6. Referencias bibliográficas.

\section{Introducción}

No es infrecuente que, tras la demanda de una intervención familiar, la familia haya tenido una experiencia previa en otros contextos de trabajo, orientados de ordinario al miembro individual. En general, el sistema familiar ha identificado a un paciente portador de un diagnóstico; cuando el diagnosticado es un niño o una niña, el trastorno de déficit de atención con hiperactividad (TDAH) suele ser uno de los de mayor prevalencia.

Una de las autoras del presente artículo desarrolla su actividad profesional como profesora de educación primaria, y realiza simultáneamente su formación de postgrado en intervención familiar. Es precisamente en la interfaz entre ambos mundos (escolar y de in- 
tervención terapéutica) donde cobra sentido el abordaje comprensivo del trastorno de déficit de atención con hiperactividad. Los profesores asisten diariamente a lo que se puede denominar una «inflación» diagnóstica en niños y niñas. Este juicio se convierte en el modelo explicativo dominante de la conducta del menor, que en numerosas ocasiones oscurece otras partes de su realidad, en especial la dinámica familiar y el contexto social en los que se desarrolla su vida.

La terapia familiar sistémica ofrece una lectura de la realidad particularmente fecunda, procurando desentrañar los factores familiares y socioculturales que facilitan la comprensión de la conducta, así como arrojar luz también sobre el modo como los propios protagonistas los representan, viven y expresan en contextos específicos (Blais, 1995).

Las aportaciones del trabajador social, Michael White $(1994,2002,2002 a)$ son especialmente fecundas y esclarecedoras, a los fines de esta introducción. El diagnóstico psiquiátrico esconde - según el autor - un peligro que reside en la desresponsabilización que puede experimentar el paciente. A través del diagnóstico - prosigue - se asume que lo que hace o lo que dice no es responsabilidad de la persona sintomática o diagnosticada, sino que su comportamiento se debe a su enfermedad; de manera que el diagnóstico es como un telón que tapa otras historias y secuencias que se suceden dentro del grupo familiar o en el contexto del sujeto. Siguiendo el importante hilo conductor de White, la labor del profesional sería «localizar la puerta de entrada», levantar el telón poco a poco e ir avanzando hasta una «superficie de reflexión» en la que se puede dialogar y pensar en el sistema familiar sin que sea el síntoma, el diagnóstico, lo que dirija y explique todos los sucesos o acciones. En esta línea, el objetivo general de la intervención familiar es, con sus palabras, «la generación de historias alternativas que incorporen aspectos vitales y anteriormente negados a la experiencia vivida» (1994, p. 46).

Por otro lado, el diagnóstico no se da en el vacío, sino que es expresión del entorno sociocultural y científico de cada momento. Asistimos actualmente a una inflación diagnóstica, en los contextos sociosanitarios y socioeducativos, como se ha dicho anteriormente, lo que se ha denominado la psicologización de la vida cotidiana, con el consiguiente «peligro de favorecer un reduccionismo psicológico o biológico de fenómenos y realidades que son mucho más complejas y de empañar otras perspectivas que explican mejor y de forma más global el sufrimiento» (Ortiz Lobo, 2011).

La perspectiva sistémica en el abordaje de la familia nos acerca a una mirada holística y reflexiva que procura evitar la influencia de la etiqueta diagnóstica en la vida de las personas. A través del análisis de un proceso de intervención de cinco meses de duración, con la frecuencia de una entrevista cada quince días que se ha llevado a cabo en un contexto de formación-supervisión, se expone el modo como el abordaje sistémico de las dificultades personales y familiares posibilita un resultado más esperanzador y ético, a la par que se activa a los propios protagonistas o actores para que procuren hacerse con las riendas de su destino. Es nuestro interés dejar patente la necesidad de huir de la visión simplista, según la cual la intervención terapia familiar implica psicopatologizar las situaciones y los problemas.

\section{Niños problemáticos, niños con trastor- nos, familias con dificultades}

Javier llegó al nuevo colegio en cuarto curso. Traía consigo un diagnóstico de trastorno de déficit de atención con hiperactividad, que le acompañaba desde que tenía 7 años. También portaba una historia: había sido trasladado al nuevo colegio porque semanas antes había ingresado, junto con su hermano discapacitado, en una residencia de menores. Su madre había sido hospitalizada debido a una profunda depresión, al parecer producida porque su marido, y padre de Javier, había sido detenido y encarcelado meses antes por haberles proporcionado malos tratos, a ella y a sus hijos, entre otros delitos y actos violentos.

Alejandro y Antonio se llevan cuatro años. Son hermanos de madre, pero no de padre y conviven con la actual pareja de la madre (que es padre del último), y con otros dos hermanos mayores (de otro padre diferente). Los padres de Alejandro no tienen ninguna relación, y si coinciden en algún momento está asegurada la discusión. Alejandro pasa dos días por semana con su padre. Su madre le pide que llame «papá» a su actual pareja, y tiene absolutamente 
prohibido hablar de su padre biológico en su presencia (y de su madre en presencia de su padre). A partir de los cuatro años, Alejandro empezó a mostrar importantes dificultades en la escuela, en términos de concentración, una excesiva actividad motora, etc. A petición de las profesoras, el pediatra sugirió un estudio neurológico, pero no existía ninguna anomalía neuronal, y aun así, se le recetó la medicación para tratar un trastorno de déficit de atención con hiperactividad. La madre comenzó el tratamiento, pero a las pocas semanas lo dejó porque: «no se ponía de acuerdo con su padre, [...], se le olvidaba darle la pastilla [...], el niño estaba como triste y era muy cara». Actualmente, Alejandro no está medicado y Antonio muestra exactamente los mismos síntomas que su hermano mayor: ambos están en proceso de una evaluación psicopedagógica.

Lorena tiene 8 años. Vive con su madre de 24, su abuela materna y su tía de 11 años en la casa de una señora de 95 años, a quien cuida su abuela. Tres personas comparten habitación excepto la joven madre que dice: «No puedo dormir con Lorena porque se mueve demasiado». Actualmente se encuentra sin trabajo, y aun así exclama: «no puedo hacerme más cargo [...], tengo mucho que hacer y sólo pido a mi madre que me ayude». Su madre, la abuela de Lorena, comenta: «yo tengo a mi hija [la tía de Lorena] y a la señora que cuido». Mientras se aclaran, ¿quién cuida, atiende y abraza a Lorena? Desde el colegio ya se ha elaborado un protocolo para estudiar su déficit de atención.

Estos son sólo tres ejemplos de los cientos que podríamos relatar, si nos fijáramos en los diferentes entornos escolares. Todos ellos serían clasificados como niños problemáticos, cuya conceptualización es muy amplia, de acuerdo con Harwood (2009). Compartimos con la autora, la importancia de que utilizar la palabra diagnóstico como parte exclusiva de un acto clínico oficial, «implica perder de vista los efectos de las prácticas sociales generales» (p. 17); es decir, con el diagnóstico sólo marcamos, trabajamos e investigamos en caso individual, sin atender a su entorno social más cercano.

En la narración breve de los casos se ha querido explícitamente introducir, como parte fundamental, el entorno familiar de los futuros (ya presente para uno de los casos relatados) del trastorno de déficit de atención con hiperactividad, que tantas veces se obvia en las escuelas, y en los despachos de muchos profesionales. Un diagnóstico en los niños, su etiquetado, no sólo tranquiliza a los profesionales, también «hace más fácil» al entorno del niño o de la niña pensar en las dificultades no tanto desde su propia responsabilidad o del propio entorno, sino a partir de ese mismo diagnóstico. Obviamente la laxa conceptualización de «niño problemático» tranquiliza menos, en términos de responsabilidad, que la de un niño con un trastorno, con una psicopatología inevitable, que justifica cada uno de los actos del sistema familiar. El diagnóstico evidentemente también puede angustiar, pero deja a los padres sin recursos y sin capacidad de maniobra, puesto que lo que ocurre, su solución, corresponde a un experto.

Tanto Harwood como White (1994) articulan las nociones foucaultianas de poder y verdad para repensar los contextos profesionales. Uno de estos contextos, la escuela, es especialmente sensible a lo que una docente denominaba «modas diagnósticas»; le escuchábamos decir: «En los veinte años que llevo trabajando hemos pasado por tantas modas: primero era no sé qué, luego la dislexia, ahora el TDAH». En el aula, la etiqueta diagnóstica se requiere especialmente a los alumnos que muestran mayores carencias, con el deseo de darles la mejor atención posible, y no para «quitarte de encima al niño/a conflictivo». Por supuesto que el tutor conoce los problemas familiares, son muy evidentes, pero la escuela sólo puede hacer una labor tutorial, además de intentar establecer redes con otras instituciones que puedan ayudar al alumno y a sus familias. Mas desgraciadamente para que esa red se constituya y un especialista atienda a las familias, las instituciones obligan a realizar un protocolo que necesariamente ha de empezar por «marcar» al alumno. La verdad estaría en la etiqueta, que es a su vez el pasaporte para recibir una atención de otras instituciones, que son las organizaciones que tienen el poder para trabajar directamente con las familias.

Es inevitable, aunque sea brevemente, describir, el diagnóstico del trastorno de déficit de atención con hiperactividad. El Manual Diagnóstico y Estadístico de los Trastornos Mentales (Diagnosis and Stadistical Manual of Mental Disorders), lo publicó la Asociación 
Americana de Psiquiatría en Estados Unidos en 1952. En esta primera publicación no se habla de trastornos infantiles ni de niños problemáticos. El manual ha sido revisado y se han ido añadiendo diferentes enfermedades y síntomas hasta la publicación actual, el DSM-IVTR, en la que se contempla el trastorno de déficit de atención con hiperactividad, como un trastorno del comportamiento caracterizado por la distracción, de moderada a grave, los periodos de atención breve, la inquietud motora, la inestabilidad emocional y las conductas impulsivas, entre otras. En la actualidad afecta, según Freire (2012), en una proporción que va del 5 y al 10 por ciento de la población infanto-juvenil española, aunque según algunas fuentes, existe un 75 por ciento de casos sin identificar. Así mismo, señala que el diagnóstico ha aumentado en los últimos veinte años el 300 por ciento en la población estadounidense.

No es nuestro propósito cuestionar ni poner en entredicho el trastorno de déficit de atención con hiperactividad como categoría diagnóstica, sólo se propone, como se ha venido reiterando, «salir» de la «verdad» de la categoría diagnóstica, que siguiendo a Harwood (2009) hace que un menor se defina a sí mismo como problemático, al asumir su psicopatología y su incapacidad, e intentar darle un sentido, así como usar el «poder» de las instituciones (maestros, pediatras y psicólogos) para romper dicho trastorno, en palabras de Ubieto (2013) como discurso y como institución que genera una manera de vincularse con el otro.

\section{La familia Soler ${ }^{1}$}

La familia de la que se hablará a continuación, a través del relato de la intervención sociofamiliar realizada, acudió a terapia familiar, al haberla derivado un profesional, debido a los problemas en su funcionamiento y a la preocupación por uno de los hijos diagnosticado como trastorno de déficit de atención con hiperactividad.

Nuestra «paciente» cumplía a la perfección con el perfil de dificultades en la escuela asociadas a ese tipo de trastorno: dificultades para escuchar al maestro y a los compañeros y para permanecer sentada, para leer textos largos o para trabajar en tareas monótonas (tareas todas ellas verdaderamente difíciles para el niño con dicho trastorno), además de que desarrollaba diversas conductas disruptivas dentro del aula. Asimismo, en casa era desobediente y causaba muchos problemas a sus padres y en su entorno.

Se analizará el caso de la familia Soler como un paradigma del diagnóstico como organizador, al que hacíamos referencia anteriormente. Más allá del proceso previo en el que se realizó el diagnóstico — no hemos tenido acceso a informes médicos, y no sabemos si ha habido un estudio neurológico o si se investigaron posibles causas genéticas - nuestro propósito es poner de manifiesto su locus en el funcionamiento de la estructura familiar.

La familia Soler está formada por cuatro miembros: el matrimonio, Lucía y Paco, de 41 y 44 años de edad y Laura y Pedro de 12 y 10 años, respectivamente. El padre trabaja de manera autónoma como camionero. Está 16 horas diarias en ruta, sólo libra un día a la semana; la madre está en paro y busca trabajo.

Según narra su madre, Laura es una niña que ha mostrado importantes diferencias con sus iguales desde que tenía cuatro años: fue diagnosticada por problemas del lenguaje, mostraba diversas dislalias, además de un cierto retraso madurativo. Empezaron entonces los diversos tratamientos y ese primer diagnóstico se convirtió a los pocos años en la definición de trastorno de déficit de atención con hiperactividad. Los padres se muestran desesperados porque no observan grandes avances, tras ocho años de terapia individual, dos años de terapia en grupo con otros niños con su enfermedad y dos tipos distintos de tratamiento farmacológico. Laura, por su parte, nos cuenta que ella y su hermano acuden desde hace dos años a un colegio «para niños con hiperactividad, dislexia [...] con discapacidad». Cuando le preguntamos a la niña si le gusta el colegio o si tiene muchos amigos, los padres empiezan a contestar por ella, y resulta difícil redirigir la conversación a la niña.

Ésta es una de las pautas que se repite a lo largo de la intervención, especialmente en es-

1 Los nombres de todos los miembros de la familia han sido modificados para evitar que sean identificados. 
tas primeras entrevistas, y que dificulta entender las versiones de los diferentes miembros de esta familia.

Según Paco, el padre, «Laura siempre es el punto discordante, es inquieta y desobediente», añade que la niña se siente culpable y señalada en el colegio por compañeros y profesores. En este punto, Laura, que está sentada entre sus progenitores, se abraza a su padre y comienza a llorar desconsoladamente. Lucía, la madre, por su parte expresa su frustración porque a su hija todos «la entienden, pero no lo han asumido [su enfermedad] como yo». Laura también tiene problemas con la familia extensa y enfrenta a abuelos, tíos y primos porque, según Paco, nadie lo entiende: «porque sus hijos son normales, bueno en realidad son anormales de los buenos, listos y obedientes que son».

Por su parte, Pedro, el hermano, en nuestra indagación del sistema fraterno, nos cuenta que Laura y él se pelean porque ella siempre «tiene que salirse con la suya y me pega». Pedro ha repetido segundo de Primaria y su hermana cuarto.

Otras informaciones que nos resultaron muy útiles para comprender mejor la situación y comenzar a armar el «contexto terapéutico» fueron que la madre, Lucía, ha acudido igualmente a terapia individual durante tres años; afirma que sentía que necesitaba ayuda, «unas pautas para tratar a la niña», porque se sentía además muy sola y, a la vez, muy cuestionada por la familia de origen de su marido, con quien tienen un trato muy cercano. Por otro lado, también el matrimonio ha acudido a terapia de pareja durante un año. Finalmente, nos llama la atención el hecho de que Laura muchas noches se mete en la cama con su madre, quien reconoce su error, pero a la vez dice: «necesito esos momentos», porque tiene vacíos que consigue llenar con su hija.

Hasta aquí la narrativa de la familia, a la que hay que añadir la observación de sus pautas interaccionales: la niña entre sus padres y el hermano al lado de su madre; el llanto no justificado de la niña y, cuando intentamos hablar con ella, la búsqueda de protección en su padre lo que provoca, a la vez las lágrimas de la madre; si le pedimos que espere porque está participando otro miembro de la familia, llama la atención del padre o de la madre; o cuando el hermano se queja de que ella siempre se sale con la suya, la niña se sonríe, etc. Todo ello nos permite realizar algunas hipótesis sobre la estructura familiar que marcarán las líneas de intervención o de trabajo; unos mapas, en definitiva, que nos permitan ampliar el foco a las relaciones familiares, trascendiendo la categoría diagnóstica.

Siguiendo la clásica conceptualización de Minuchin (1977), planteamos algunas hipótesis: nos hallamos ante una familia aglutinada en la cual la conducta de un miembro afecta de inmediato a los demás y el estrés de un sujeto repercute intensamente en los otros. Así se pone de manifiesto que el llanto de la niña aflige enormemente a ambos progenitores; todos ponen palabras al pensamiento de los otros y los límites se muestran muy difusos, sobre todo, en el momento en el que la niña acompaña la soledad de su madre.

Asimismo se observa un padre en una posición muy periférica. Refiere que sus horas fuera de casa hacen que no le informen de muchas de las cosas que suceden en la cotidianeidad familiar; en esta línea, se da una triangulación madre-hijos (siempre recurren a ella ante el conflicto, con las tareas del colegio, si necesitan ayuda, etc.) teniendo poco en cuenta al padre. Todo lo antedicho hace que los procesos de diferenciación de los distintos miembros de la familia estén perturbados (Bowen, 1991), y cuyas consecuencias son evidentes: dificultades de relación con los iguales y lenguaje infantilizado de ambos niños, entre otros.

Además de la organización familiar es oportuno hacer referencia al tipo de demanda relacional que realizan los padres. Tienen una hija de 12 años que lleva ocho en el «taller de reparaciones»; que han probado distintas terapias y tratamientos, incluso farmacológicos y, a pesar de lo frustrante de los mismos, siguen buscando «recetas mágicas» para lidiar con los problemas que les causa la conducta sintomática de su hija. De modo que se colocan frente al tercero en una posición down - dejan los roles parentales en manos de los profesionales - lo que implica en cierto modo una delegación de las responsabilidades de su parentalidad. Pero paradójicamente esta propuesta relacional produce cierta sensación de fracaso en los padres, que sienten el no ser capaces de ayudar ni de salir adelante con los problemas de sus hijos. 
Por último, no es inocuo el cuestionamiento del entorno - la familia extensa y los amigos-, de hecho la pareja de padres acudía a terapia en secreto, por miedo a que se les juzgara por su fracaso en cuestiones parentales, según ellos mismos expresan.

Con estas hipótesis, el primer planteamiento fue realizar cambios estructurales en el funcionamiento de la familia; es decir, delimitar los roles y funciones de cada uno para satisfacer las necesidades individuales y las del sistema. Para ello fue necesario vislumbrar el rol que jugaba el diagnóstico o el síntoma en el sistema familiar. Cuando se piensa en los problemas del niño, desde un punto de vista sistémico, la consideración más importante es quizá determinar cómo interactúa la familia en torno a los síntomas. En esta línea, Wachtel (1994) plantea que el profesional,

Debe tratar de averiguar no sólo en qué beneficia dicho síntoma a otros miembros de la familia, o qué estará pensando el niño que otros familiares no puedan expresar por ellos mismos, sino también qué conducta parental específica alienta o acepta implícitamente los síntomas del niño (p. 116).

\section{El niño que transita por diferentes sub- sistemas}

¿Cómo se ha de proceder para trascender el síntoma? No sirve exclusivamente su confrontación porque, como se decía anteriormente, es mucha la verdad y el poder que esconde. Mas centrarnos continuamente en la enfermedad implica confirmar la idea de la familia de que el síntoma es la única parte afectada del sistema, y convertir a la niña sintomática en un chivo expiatorio. Con esta idea, en la segunda entrevista nos centramos en el ciclo evolutivo de la familia, con el objetivo de expandir el foco y poder entender cómo habían alcanzado ese nivel de fusión tan alto entre los miembros y por qué las fronteras y límites se encontraban tan difusos.

Lucía, la madre, tomó la palabra y relató que con 16 años y desde Almería se vino a Madrid a vivir con su abuela. Nada más llegar conoció a Paco, historia que relata con cariño, pero con cierto resentimiento. Después del nacimiento de Laura, falleció la abuela de Lucía, y por el especial cariño que le profesaba, verbalmente le dejó en herencia su casa. Sin embargo, la madre de Lucía le dice que la casa no será para ella. Además, su propia madre no la acompañó durante el parto ni en la celebración de su boda. Lucía decide no luchar por esa casa y se van al pueblo, donde la familia de $\mathrm{Pa}-$ co tiene otra casa, e inician allí un nuevo periodo. Lucía reitera que la decisión la tomó ella, no contó demasiado con la opinión de su marido para este cambio: renunciar a lo que legítimamente le pertenecía, no enfrentándose así a su familia de origen pero despareciendo en lo que a ellos respecta.

Viven dos años en el pueblo. Tras el nacimiento de su segundo hijo, Paco cansado de ir y venir a Madrid donde trabajaba, propone volver a vivir en Madrid, en casa de sus padres, hasta que les den el piso que esperan. Finalmente, su mujer accede no muy convencida: «fue un gran error», porque la convivencia con los suegros fue muy difícil para Lucía, que se sentía cuestionada continuamente por la familia extensa de su marido e inició un tratamiento psicológico. Dos años después se mudaron a su actual vivienda. Laura tenía cuatro años y comenzaron los diagnósticos y tratamientos de la niña.

Relatan ambos hechos con tensión, con mutuas interrupciones entre los cónyuges. En general, ambos se sienten dolidos por las dos decisiones que ha tomado cada uno de ellos por su lado. Los chicos comentan que se ponen muy tristes porque ven que a su madre esto le provoca tristeza, y Laura arranca a llorar desconsoladamente. Se verifica la idea de límites difusos, en el que el dolor de uno de los miembros afecta enormemente a todos ellos, y el hecho de que algunas decisiones importantes de los cónyuges se hayan producido sin contar demasiado con la opinión del otro, nos da pistas de que algo no funciona en el subsistema conyugal.

En el trabajo de delineamiento de límites es imprescindible conocer el pasado para ayudar a trazar la nueva historia familiar en la que puedan ser satisfechas las necesidades de todos los miembros de la familia, ya que los procesos de diferenciación están ligados a las pautas transicionales de los cónyuges con sus respectivas familiares de origen y por la relación entre ellos.

\subsection{Trabajando con la fratría}

El funcionamiento de la fratría es extremadamente asimétrico. La «norma» de la casa es 
que la mayor, Laura, y sus síntomas son los que mandan. Una parte del cuestionamiento es señalar y desafiar al hermano menor a que luche o «pelee» más por sus intereses. No puede porque su hermana es «imposible» y porque su madre le aconseja que evite las peleas. Él dice que está de acuerdo, aunque se muestra visiblemente enfadado: "siempre me tengo que aguantar». Sin embargo, no hay unanimidad, el padre le dice a Pedro que se defienda más frente a Laura (porque tampoco sabe defenderse en otros contextos, como en el colegio con sus iguales).

A diferencia de Lucía el padre, Paco, se muestra menos tolerante con Laura, de quien afirma que «se cree el ombligo del mundo [...] está acostumbrada a conseguir siempre la atención y eso no le vale en la calle, y por eso no tiene muchas amigas de su edad y tiene problemas en la escuela». Por otro lado, la madre cree que su marido es demasiado autoritario con los hijos y que éstos se asustan, reconociendo que ella misma se repliega si Paco se altera. No obstante, expresa culpabilidad y dudas acerca de si lo está haciendo correctamente. Refiere no querer repetir con sus hijos el patrón de su propia madre, a quien califica de comportarse de modo muy estricto con ella, por lo que quiere dejar más libertad a Laura y no estar constantemente encima de ella. Lucía dice que ha pasado de alterarse, también ella, a tratar de ser más paciente o hablar con la niña para hacerle entrar en razón (por lo que cuenta, parece que influenciada por las pautas recibidas en terapias anteriores, utiliza términos como economía de fichas y otros procedimientos utilizados para la modificación de la conducta, basados en refuerzos positivos y negativos, reconociendo que a veces termina dejándola hacer lo que quiere para evitar un aumento del conflicto con ella.

Por nuestra parte, apoyamos la preocupación que los padres han ido exponiendo en las entrevistas por las dificultades de Laura, señalando que el diagnóstico de retraso madurativo ha sido un factor que ha podido ralentizar el proceso de la menor (lo utilizamos con la intención de desculpabilizar a los progenitores), pero centrando la atención en cómo podrían ambos, y también Pedro, ayudarla a crecer.

Se destaca que «las palabras no parecen estar sirviendo» (recordemos la multitud de es- pacios terapéuticos), en este punto el padre piensa que quizás su hija necesite un internado, a lo que se les devuelve que «por qué no actuáis en casa con la idea de cómo funciona un internado».

\subsection{El subsistema conyugal}

Tras el trabajo con el subsistema fraternal se decidió citar sólo al matrimonio para trabajar exclusivamente con las cuestiones referentes a este subsistema: establecimiento de límites más claros con sus hijos, con el objetivo básico de ayudarles a crecer.

Lucía se siente reñida, cuestionada, atacada por Paco: «gruñe y levanta el tono de voz de manera inconsciente [...] yo estoy tranquila cuando él no está en casa». Paco por su parte siente que es el malo porque es siempre él quien regaña, dando muestras, una vez más, de lo apartado que se siente del funcionamiento de la familia. De hecho Lucía afirma que: «los chicos se portan bien y todo funciona hasta que él llega». Se pone en evidencia cómo lo parental y lo conyugal están imbricados, porque Paco tiene deseos de ser padre, de tener un lugar. Se le señala a Lucía que tiene un marido deseoso de ser padre, y que nos preguntamos por qué no lo usa. Asimismo, la «presencia del padre» ayudaría a los chicos a crecer, que son los que están teniendo verdaderas dificultades, ella sola no va a poder.

El feedback de Lucía fue: «me siento sola, añoro a mi marido»; Paco se emociona y dice entenderla porque a él le ocurre lo mismo. Ninguno recuerda la última vez que «funcionaron como equipo de padres»; reconocen que deben marcar las diferencias con los hijos, a Lucía le cuesta más trabajo porque lleva «mirando continuamente» a su hija desde que nació y de manera muy especial desde los cuatro años (recordemos que es cuando se hizo el diagnóstico). Fueron muchas las ocasiones en las que repetimos «lo mucho que necesita Lucía a Paco para que los niños crezcan y tengan menos dificultades». Además, como cónyuges, esta entrevista nos sirvió, en adelante, para recordar la idea de «dejar a los chicos fuera».

\section{Días de reflexión: el camino para el cambio} A lo largo de las siguientes entrevistas fueron muchas las estrategias que se utilizaron para el cambio. Se reforzó la fratría y se ayudó a la re- 
solución de conflictos con técnicas de escenificación para crear intensidad. El mensaje a los padres es bastante claro: «la experiencia en la fratría les ayudará también a «crecer» y a desenvolverse fuera de la familia». La madre puede expresar por primera vez su preocupación por la dependencia tan acusada de Laura, ya que tiende a recurrir a su madre para que la defienda en las desavenencias con sus iguales. La progenitora refiere sentirse desconcertada, ya que unas veces ve a su hija «peleona y otras muy empequeñecida». En este mismo sentido el padre dice sentirse «desarmado» porque «Laura se siente la más débil, pero no creo que en realidad lo sea». Aprovechamos esta reflexión e intervenimos con el mensaje de cómo «esta debilidad» en realidad «le da fuerza y poder dentro de la familia». Llorar en lugar de negociar la convierte en una niña pequeña; y el hecho de conseguir todo lo que quiere no le ayuda a ver que ése no es el camino para acceder a lo que se desea.

Otro camino que se cruza con el anterior, es el lugar que han ocupado en la familia las opiniones de los diferentes especialistas. Es Paco, el padre, el que trae este discurso: «es así como nos han aconsejado que debemos de tratar a la niña [...] actualmente Laura no toma ninguna medicación porque no le favorece en ningún aspecto. Aunque sigue acudiendo al psicó$\log 0$ y a terapia de grupo con otros niños». Momento en el que interviene Laura y plantea que le parece: «una pérdida de tiempo porque no hacemos nada allí [...] a mí me gustaría hacer otras cosas como gimnasia rítmica o patinaje, pero mis padres no tienen dinero para que me apunte a eso».

Por su parte, Paco no quiere que Laura vaya más a terapia, «porque los niños no van a terapia», le parece que el hecho de que lo haga su hija, le convierte en una niña distinta a los demás. Lucía, por el contrario, lo considera «beneficioso» porque le proporcionan una serie de pautas con la niña y le parece que «está más tranquila». Lanzamos de nuevo la pregunta:

¿Por qué no os usáis más a vosotros mismos? Porque, en el fondo, los mejores terapeutas para los hijos sois los padres, convivís con ellos todo el día, no sólo el ratito de terapia. Con lo que los dos sabéis, por vuestras experiencias propias y porque conocéis a vuestros hijos me- jor que nadie, sois muy capaces de saber lo que pueden necesitar o hasta dónde pueden llegar en las diferentes situaciones.

En la penúltima entrevista, la madre dijo que colabora como voluntaria en un centro del barrio, algo que le hace sentirse muy feliz porque está deseando encontrar trabajo. Por su parte, Laura empieza a dar señales de querer hacer cosas con las amigas: salir al parque, ir a dormir a casa de una de ellas, etc. Le pedimos entonces que haga a sus padres estas demandas de manera adecuada. Al principio intenta que su madre medie entre su padre y ella en la negociación, quien, apoyando nuestra línea de trabajo, se mantiene al margen con un «a mí no me lo digas, habla con tu padre». Finalmente, consigue hablar "como una chica mayor» directamente con su padre. Las profesionales lo celebramos y le felicitamos efusivamente porque «ya tiene doce años». A lo largo de la entrevista reforzamos este mensaje y le pedimos a Laura que ayude a su hermano, con consejos acerca de cómo pedir las cosas. Paco, emocionado, se levanta de su silla y abraza a su hija. Ambos progenitores afirman que observan «un gran cambio» y se muestran orgullosos. A pesar de su alegría, cuando las demandas de los chicos se materializan (Laura quiere quedarse a dormir con una amiga del colegio), parece que es ahora Paco quien se muestra más reacio a dejarlos solos. La sobreprotección de Lucía «tapaba» que a su marido también le cuesta separarse de los chicos. Se les devuelve a Laura y a Pedro que «lo van a tener difícil», pero que han de encontrar nuevas vías para «pelear y negociar» sus intereses acordes a su edad, ya que «vuestros padres os ven más pequeños» de lo que son.

Ante estos cambios tan positivos y favorables, nos despedimos de la familia Soler, pensando en lo valiosa que es la familia como recurso terapéutico, como herramienta de cambio.

\section{Conclusiones}

La intervención familiar trasciende la noción cosificadora de la categoría diagnóstica (trastorno de déficit de atención con hiperactividad, «niño problemático», etc.) para procurar una comprensión del contexto de los niños y niñas, que permite ampliar los recursos de la familia y de los propios profesionales. 
El trabajo centrado en la estructura familiar que subyace a la conducta sintomática (Minuchin, 1974; Minuchin y Fichman, 1983; Wachtel, 1994; Minuchin, Colapinto y Minuchin, 2002) ofrece una perspectiva llena de posibilidades para los profesionales, ya que se trata de un modelo sencillo y palmario, según el cual la persona influye en su medio y es influida al mismo tiempo por éste. Así, las modificaciones en la estructura familiar contribuyen a la producción de cambios en la conducta y en los procesos psíquicos internos de los sujetos. Por otro lado, para la familia porque implica tener la oportunidad, el espacio y la voz para poder trasmitir al otro, a los otros, sus ideas, sensa- ciones, sentimientos, lo que ayuda en gran medida a la satisfacción de necesidades.

Por último, la unión del profesional con la familia, tal y como se ha desarrollado el proceso de intervención expuesto, no es para educarla o socializarla, sino para que a través de diversas técnicas - cuestionamientos y comentarios - trate de modificar su funcionamiento de manera que prosiga el ciclo evolutivo con éxito. Estos son los cambios que tienden a perpetuarse porque tienen el valor de lo propio, de modo que el proceso que un profesional empieza con una familia sea mantenido en su ausencia gracias a los mecanismos de autorregulación de aquélla.

\section{Referencias bibliográficas}

Blais, L. (1995). Étiologie sociale et santé mentale: ouvertures et fermetures des modèles explicatifs dominants. Reflets, 1(2), 138-162. Recuperado de: http://id.erudit.org/iderudit/026080ar.

Bowen, M. (1991). De la familia al individuo. Barcelona: Paidós.

Freire, H. (2012). Infancia y trastorno. ¿Niñas y niños hiperactivos? Cuadernos de Pedagogía, 419. Disponible en: http://www.cuadernosdepedagogia.com/content (consultado el 12/04/2013).

Harwood, V. (2009). El Diagnóstico de los niños y adolescentes «problemáticos»; una crítica a los discursos sobre los trastornos de la conducta. Madrid: Morata.

Minuchin, J., Colapinto, J. y Minuchin, S. (2002). Pobreza, institución, familia. Buenos Aires: Amorrortu.

Minuchin, S. (1974). Familias y terapia familiar. Barcelona: Gedisa.

Minuchin, S. y Fishman H. (1983). Técnicas de Terapia Familiar. Barcelona: Paidós.

Ortiz Lobo, A. (2011). Iatrogenia y prevención cuaternaria en los trastornos mentales menores, 313-323. Recuperado de: www.alansaludmental.com (consultado el 08/012013).

Ubieto, J. R. (22 de abril de 2013). La «institución» del TDAH. El blog de José Ramón Ubieto. [On line]. Disponible en: http://joseramonubieto.blogspot.com.es/ (consultado el 23/04/2013).

Wachtel, E. F. (1994). La clínica del niño con problemas y su familia. Buenos Aires: Amorrortu. Watzlawick, P., Beavin J. y Jackson D.D. (1981). Teoría de la Comunicación Humana. Barcelona: Herder.

White, M. (1994). Guías para una terapia familiar sistémica. Barcelona: Gedisa.

White, M. (2002). El enfoque narrativo en la experiencia de los terapeutas. Barcelona: Gedisa. White, M. (2002). Rescribir la vida. Barcelona: Gedisa.

White, M. y Epston, D. (1993). Medios narrativos para fines terapéuticos. Barcelona. Paidós. 